\title{
The Intersection between Language, Culture, Race and Ideology Reflections on the Translation of African-American Literature into Arabic
}

\author{
Saddik Gohar* \\ UAE University
}

*Corresponding Author: Saddik Gohar, UAE University, UAE

\begin{abstract}
Incorporating trans-cultural elements as integral part of translation, Peter Newmark in A Textbook of Translation, defines culture as "the way of life and its manifestations that are peculiar to a community that uses a particular language as its means of expression" (Newmark 1988).Caught between the complicated intricacies of SL and TL cultures, translation often engages " two languages and two cultures" (Toury 1978 ) because "no language can exist unless it is steeped in the context of culture, and no culture can exist which does not have at its center, the structure of natural language" (Lotman et al 1978). Because "language is part of a culture" (Vermeer 1989), translation theorists emphasize the significance of linguistic and cultural variations in the process of translation from SL into TL. In this context, the paper explores the linguistic and cultural hurdles embedded in the translation of African-American literary texts into Arabic due to differences in cultural and linguistic traditions. Since "differences between cultures may cause more severe complications for the translators than do differences in language structure " (Nida 1964) and because the attempt " to impose the value system of the SL culture onto the TL culture is dangerous ground" ( Bassnett 1991), more emphasis will be given to translation problems rooted in cultural transfer. On this basis, the paper starts with a systematic methodology and an entrance to translation strategies suitable for rendering SL culture-specific realia into TL context. Then, a survey of potential semantic and cross-cultural problems encountered in the translation of literary texts will be conducted using Dutchman, an African -American drama, as an example of literary texts which often present challenges to translators.
\end{abstract}

\section{INTRODUCTION}

In a globalized and eventful era, characterized by an unprecedented revolution in human knowledge, the tendency to underline the significance of advocating a cultural approach to translation became inevitable. In this context, Gideon Toury argues that "translation is a kind of activity which inevitably involves at least two languages and two cultural traditions" (Toury 1978: 200). Exploring the intersection between language and culture, Peter Newmark, in A Textbook of Translation, defines culture as the way of life and its manifestations that are peculiar to a community that uses a particular language as its means of expression (Newmark 1988: 94). However, the importance of cultural differences compared to linguistic differences in translation was raised for the first time in the theories of Eugene Nida who attributed equal importance to both of them emphasizing that distinction between cultures may cause more severe complications for the translator than do differences in language structure. (Nida 1964: 130). In Translation Studies, Susan Bassnett also underlines the connection between language and culture pointing out that language is "the heart within the body of culture". According to Bassnett, the linguistic notions of transferring meaning are seen as being only part of the translation process, thus, "a whole set of extra-linguistic criteria, must he considered." Further, she argues that "the translator must tackle the SL text in such a way that the TL version will correspond to the SL version. To attempt to impose the value system of the SL culture into the TL culture is dangerous ground. (Bassnett 1996: 23).On this basis, it is apparent that culture is an integral part of the texture of language and since different languages use different linguistic systems, no language can adequately express the meaning of another.

Therefore, an understanding of the significance of cultural differences compared to linguistic variations with regard to the theory and practice of translation is important because "different languages segment experience in different ways" (Nida 1964: 88). The existence of different 
semantic segmentation between languages acquires significance when a translator is confronted with the dilemma of translating cultural realia unknown to the speakers of the target language. In literary translation, texts are often loaded with culture specific aspects, analogies and allegories which cannot be adequately rendered into TL without a considerable level of cultural knowledge on the part of the translator. During translation, it is crucial for the translator to consider not only the lexical impact on the TL reader but also the manner in which cross-cultural aspects are perceived and processed in the TL text.

Due to the intricate relationship between language and culture, translation is not only a dynamics for transferring textual/semantic knowledge but also a means of Trans -cultural communication. During the process of translation, the translator plays the role of a mediator between two cultures and two different world views. Since translation is concerned with both language and culture indicating the movement of ideas, literatures, technologies and values between different geographical destinations, the translator should take into consideration the SL cultural aspects and how they are transferred

to TL contexts. Caught between the need to capture the peculiarities of source language (SL) texts and the need to address TL readership, the translator should be aware of the entanglements of two cultures at least. Because translation is not only a linguistic phenomenon but also a cultural construct, the cultural implications integral to the translation process may take several forms ranging from lexical content and syntax to ideologies and ways of life in a particular culture.

\section{Translating SL Dramatic TeXts into TL ConTeXts}

Since the paper will use Dutchman, an African-American play as an example of problematic texts confronting translators, it is noteworthy to spot light on the mechanism of translating texts written for the theater. In Translation Studies, Susan Bassnett reveals the differences between the translation of dramatic texts written for the theater and the translation of other literary

Texts: "The dramatic text cannot be translated in the same way as the prose text. A theatre text is read differently. It is read as something incomplete, rather than as a fully rounded unit, since it is only in performance that the full potential of the text is realized (Bassnett 1996: 120). The difficulty of translating dramatic texts, written for the theater and the failure of translators to transfer the cultural and gestural understructure of the SL text including the body language of characters leads to controversy over the literal and unperformable nature of these translated texts. Since a theatrical presentation consists of the dialectical dynamics between text and performance, it is important to preserve this connection in translation. The abandonment of the peculiar nature of the dramatic text leads to distorted translations which are deviant from the correct norms. The translator, according to Susan Bassnett, should be aware of the aspects of the written text as "a functional component in the total process that comprises theater and is characterized in ways that distinguish it from a written text designated to be read in its own way (Bassnett 1996: 121).

In this context, the translator will make a compromise between the written text and its mode of expression / performance. Apparently, the peculiarity of the dramatic text is considered as an obstacle confronting translators. Thus, the basic problem is whether to translate the dramatic text as a purely literary text or to translate it "in its function" as an element within a more complex system. Since the translation of dramatic texts, written for theatrical performance is different from the translation of other literary discourses, the focus on literalness and linguistic fidelity without using a theory of theater translation may lead to semantic complications and cultural misrepresentation. In other words, the linguistic elements, in a dramatic text, should be translated bearing in mind the assumption of their function in theater discourse.

According to theater semiotics, the linguistic system of a text is only one component of a network of interrelated systems comprising the dramatic spectacle and environment. Consequently, the translation of dramatic texts involves not only a sequence of linguistic transfers from SL to TL on the level of discourse signification but also a transfer of the function of the linguistic utterance with regard to the other component signs of the theatrical discourse. It is explicit that linguistic expressions in a dramatic text, written for the theater, consist of a structure of signs constituted not only as discourse signs but also as extra-linguistic signs. Thus, gestures, costumes, scenery, sound effects and body language are part of the signs constituting theater discourse. 
Obviously, the existence of an extra dimension to the written text which the translator should be able to comprehend implies a distinction between texts written to be read and texts written to be performed. Bassnett points out that during the translation of dramatic texts the translator should bear in mind that these texts contain distinguishable structural characteristics that make them performable beyond the stage directions. For example, the dialogue in a dramatic text is characterized by cadence, rhythm, pauses, loudness, pitch and other intonation patterns. These elements are absent in a literary text written for reading not for performance. Therefore, it is the central task of the translator to identify those structures and translate them into TL.

In Drama in Literature, Jiri Veltrusky underlines the distinctive characteristics of a text written for the theater showing how dialogue is rooted in the extra linguistic environment surrounding the characters. Emphasizing the intense and reciprocal connection between the dialogue (in a dramatic text) and the extra linguistic situation, Veltrusky points out that "the situation often provides the dialogue with its subject matter (and) the situation variously interferes in the dialogue. In its turn, the dialogue progressively illuminates the situation and often modifies or even transforms it" (Veltrusky 1977: 10). This process indicates that the total meaning of the dramatic text depends on both the extra linguistic situation and the linguistic context. The failure of the translator to keep the ideological basis of the text and the extra-linguistic criteria of the written text or the gestural patterning between SL and TL cultures would result into the dissolution in the TL text of essential structures integral to the SL text. Therefore, competent translators should avoid an over-emphasis of either the written text or its extra linguistic criteria while struggling to recreate the spirit and the effect of SL texts by using repetition, footnotes, rhetorical questions and other strategies able to reproduce foreign patterns of gestures.

\section{Selected Translation Dynamics}

In their discussions of translation strategies, Krings and Cohn provide new insight into the area of translation studies. While Krings points out that a translation strategy is the translator's "conscious plan" to tackle the major "translation problems" in the context of "a concrete translation task" (Krings 1986 : 18), Seguinot argues that there are universal translation strategies utilized by translators including "translation without interpretation", "correcting major errors immediately" and monitoring "stylistic mistakes" during the revision of the text. Like Krings, Loescher and Cohen focus on the importance of integrating the notion of consciousness in the translation process: "the element of consciousness is what distinguishes strategies from the process that are not strategic" (Cited in Gohar8). Furthermore, Lawrence Venuti states that a translation strategy involves the selection of a foreign language text and the development of an appropriate way to translate it. To Venuti, the process of domestication and foreignization are among the translation strategies (Venuti 1998: 240).

In a related context, Newmark in A Textbook of Translation distinguishes between translation methods and translation procedures. To him, translation methods "relate to whole texts" while translation procedures tackle the small units of language (Newmark 1988: 81). Newmark identifies eight translation methods as follows: The first method is the word-for-word translation in which SL word order is preserved and words are translated on a single basis using their common meanings out of context. The second method is literal translation in which SL syntactical structures are converted to their nearest TL equivalents; however, the single words are translated on a single basis out of context. The third method is faithful translation which attempts to produce the precise contextual meaning of the SL within the constraints of the TL grammatical structures. The fourth method comprises semantic translations which takes into consideration the aesthetic value of the SL text.

Adaptation is the fifth method prescribed by Newmark which advocates a free translation perspective and it is used initially to translate plays and poetry. This method aims to preserve themes, characters and plots while SL culture is converted to fit the TL cultural counterpart and the entire text is rewritten. The sixth method is free translation which aims to produce a TL text without preserving the style, form and content of the SL context. The seventh method comprises idiomatic translation which reproduces the message of the SL text but tends to distort the original meaning by incorporating colloquialism and idioms which do not exist in the SL environment. Finally, Newmark suggests what he calls the communicative translation method which seeks to transfer the exact contextual meaning of the original text into a linguistic and semantic content acceptable in the TL 
The Intersection between Language, Culture, Race and Ideology Reflections on the Translation of African-American Literature into Arabic

cultural context. Newmark also refers to a continuum existing between both semantic and communicative translation methods. To him, any translation could be "more or less semantic more or less, communicative - even a particular section or sentence could be tackled more communicatively or less semantically" because both types seek an "equivalent effect" (Newmark1988: 12). As a whole, there are two kinds of translation strategies: global and local. While the former deals with general principles, the latter refers to specific activities related to the translator's problem-solving decision making. On this basis, it is relevant to point out that translation strategies are flexible in nature including the process of acquisition, storage, utilization of data and amendments done by the translator. These strategies also involve the development of a method of translation in addition to the principles used by the translator and the objectives determined by the translating situation.

\section{THE SEARCH FOR THE SOURCE / TARGET TEXT READER}

When a text is selected for translation, the translator should bear in mind the readers/audience for whom the original text was addressed. In this context, Coulthard underlines the importance of identifying the ideal reader for whom the writer assigns "knowledge of certain facts, memory, of certain experiences and a certain level of linguistic competence" (Coulthard 1992: 9). Apparently, the preceding elements mentioned by Coulthard, are determined by the author's ideological and cultural orientations. In this regard, it is significant to refer to the nature of the text that will be used in this paper and the audience / reader category it targets. The text explored in this study is Dutchman, a short African-American drama, composed by the African American dramatist, Le Roi Jones, in 1964 during the ethnic confrontations between blacks and whites in the Unites States. Dutchman, to a great extent, corresponds to the criteria of the average text selected for translation and identified by translation theorists like Newmark and others.

Newmark in A Textbook of Translation points out that such text is basically addressed to "an educated middle class readership in an informal style" (Newmark 1988:13). Jones' ideal readers are middle class African Americans who are aware of the social, political and historical aspects shaping the racial conflict in America during the 1960's. The ideal readers of Jones possess a collective memory and a cultural consciousness determining their opinions, preferences and prejudices toward the implications of the black / white conflict. Jones does not aim to appeal to racist readership or evoke antiAmerican sentiments, however, inherent ethnic / cultural prejudices are unavoidable on the part of the African-American dramatist. Since Jones writes his play to an educated middle class audience, it is noteworthy to indicate that the source text (ST) ideal reader is established. Nevertheless, it is significant to argues that as a literary text written at a crucial stage in American history Dutchman incorporates linguistic, political, social and cultural references and allusions of great significance completely unfamiliar to the target reader (TT) in the Arab world.

After establishing the source text readership, the translator should investigate whether the ST readers correspond to their target text (TT) counterparts. According to Coulthard, the basic obstacle confronting the translator is "the construction of a new ideal reader who, even if he has the same academic, professional and intellectual level as the original reader, will have significantly different textual expectations and cultural knowledge" (Coulthard 1992: 12). Concerning the potential similarity between ST and TT readers, the translator may probably find an approximate corresponding counterpart in the target culture to replace the source culture middle class reader identified by Newmark. However, the existence of semantic and extra-linguistic variations between different cultures creates a cultural gap between ST and TT readers and it is the job of the translator to bridge this gap.

Apparently, the text of Dutchman explores the racial conflict between whites and blacks in the United States during the 1960's from the perspective of the African-American dramatist, Le Roi Jones who introduces his vision in a complicated manner engaging symbols, allusions and myths rooted in collective ethnic memory an integral to the American cultural history. The dramatist denounces the notion of assimilating the black community into the white mainstream culture. He castigates the black middle class population who seek integration into the white mainstream due to the complicated political situation in the 1960's and the institutionalized violence committed against the AfricanAmerican community. 
The Intersection between Language, Culture, Race and Ideology Reflections on the Translation of African-American Literature into Arabic

In short, the text includes two major characters, Lula, a symbol of the white American civilization and Clay, a representative of the black middle class, who seeks integration into the mainstream American culture. After an intensive verbal conflict between the two main characters over racial, historical and social issues rooted in cultural and ethnic constructs, the drama ends with the murder of Clay at the hands of Lula. From the beginning of the play, Lula (white America) dominates the action whereas Clay is placed in a defensive position attempting to adapt himself with the cultural politics of a hostile culture. Obviously, the text dramatizes the racial conflict in the US in the 1960's deploying semantic and cultural aspects peculiar to the African-American community. The text incorporates a spectrum of culturally specific expressions and analogies integral to the author's ideology and aesthetic vision. Due to the semantic and ethnic entanglements of these elements into the fabric of African-American culture, they present a challenge to both readers and translators.

In terms of ideal readership, it is apparent that the TT Arab reader has significantly different textual expectations due to local traditions, and distinctions in cultural knowledge between him/her and the ST reader. In addition to variations in the level of cultural and semantic knowledge between ST and TT readers, the use of African-American slang in the text complicates the translation process increasing the burden of the translator who finds difficulties in transferring black dialect / AfricanAmerican English into a TL counterpart. Nevertheless, certain prejudices or preferences may be automatically transposed by the TT reader who may create an analogy between the experiences engrained in the SL text and his own. For example the TT reader in the Arab world, may compare the racist policies enforced by the US Government on the black minority to governmental oppression, advocated by local dictatorial regimes against the opposition and the intellectual elite). Nevertheless, the similarity between a particular aspect of SL culture and its counterpart in the target culture TL does not match the political and social circumstances experienced by the ST readers. Therefore, culture specific concepts and semantic connotations create a gap between ST and TT readers that should be narrowed down in translations.

Concerning the text of Dutchman, it is clear that the Arabic (TT) reader is not fully aware of the foreign the above-mentioned cultural aspects embedded in the SL text. Further the linguistic and extra-linguistic differences between American and Arabic cultures complicate the process of translation posing challenges to the translator who confronts obstacles not only of a purely lexical nature but also of cross-cultural intricacies and entanglements. To solve these obstacles, the translator should be aware of the political, social and ethnic background elements integral to the play in addition to the semantic and trans-cultural ambiguities deployed in the SL text. The translator should also be aware of the connotative / denotative aspects of the SL culture particularly the culture specific expressions, the culturally-loaded vocabulary, and the African - American slang proliferated in the SL text. Depending on the translator's perception of the cultural knowledge of the TT readers, a translation strategy should be developed to determine the extend to which culturally determined items with collocational features will be explained or left for the readers to infer.

\section{Culture Oriented References in Literary Translation}

Culture-oriented references such as allusions, allegories and historical motifs provide density and depth to the SL text and need to be explicated in translations in order to reveal the richness of the SL culture for the TL readers. These culture-specific elements constitute part of the prior cultural knowledge taken for granted by an author while writing for a particular SL readership. Because languages and cultures are not identical, it is difficult to translate culture oriented aspects from one language to another, therefore, a translator may use explanatory notes. However, this procedure should be minimized as much as possible because the use of footnotes may disfigure the shape of the translated text. Due to trans-cultural distinctions and lack of socio-historical background knowledge of the SL text on the part of the TT reader, the translator should interfere to narrow the gap between ST and TT cultures. In particular situations and within the parameters of the theory of dynamic equivalence, the translator can replace SL culture-specific references with a suitable TL equivalence.

However, it is difficult to use this procedure in the Arabic translation of Dutchman due to the wide differences between Arab culture and the African-American socio- historical context. In particular cases, the translator could use formal equivalence transference regardless of the translation loss in terms of cultural connotations. Since the text of Dutchman incorporates key terms and expressions 
The Intersection between Language, Culture, Race and Ideology Reflections on the Translation of African-American Literature into Arabic

loaded with historical and ethnic associations the entire meaning of the text will be undermined during the translation process unless the significance of these lexical/cultural structures is smoothly transferred to the TL text. Because the meaning of these culture-specific items is not available to the TT reader due to lack of cultural knowledge, it is absurd to translate them into TL using either the formal or dynamic equivalence strategy. But the use of a communicative approach including an explanation of these cultural references will be an appropriate translation mechanism which familiarizes the TT reader with the cultural peculiarities of the SL text. This potential solution is not a direct translation of the ST but it aims to enable the TT reader to approach the SL culture-oriented allusions in a more meaningful manner. Further, this approach fulfills Nida's premise that a translated text should induce in the TT reader the same reactions and responses experienced by SL readers upon reading the original text.

\section{Procedures for the Translation of Culture -Specific Aspects}

According to Newmark, a cultural bound term refers to concepts rooted in a particular culture and it can be translated by the use of one of a variety of procedures and techniques. Newmark in Approaches to Translation introduces a spectrum of translation procedures/techniques. One of these procedures comprises the use of functional equivalence which involves a referent in the TL culture whose function is similar to its counterpart in the SL cultural context. In other words the functional equivalence is a translation procedure which incorporates the use of a culture-neutral term or statement. Applied to literary texts, this technique could be an idealistic method of translation; however, it could be misleading as well. Another method is the formal / linguistic equivalence which is word-for-word translation. Newmark also suggests the use of transcription or borrowing which is a kind of reproduction or transliteration of the SL text into a TL environment. According to Newmark, transcription could be accompanied by explanatory notes inserted by the translator. He refers to another technique, what he calls the self explanatory/descriptive translation which uses generic terms to convey the meaning. This method is appropriate in a wide variety of contexts where formal equivalence is considered insufficiently clear. In particular cases, it is helpful to add the original SL original term to avoid ambiguity.

Transference is also a method used in the translation of culturally determined items . It is the process of transferring an SL word to a TL text. This procedure includes transliteration or transcription. Newmark in Approaches to Translation identifies Naturalization as a translation procedure which adapts the SL items to the pronunciation and the morphology of the TL context (Newmark $1988 \mathrm{~b}$ : 82). Newmark also refers to a translation technique called Cultural equivalence, a procedure which comprises the replacement of a cultural bound term in the SL text with its potential TL counterpart. As for the use of descriptive equivalence, it is a translation procedure in which the meaning of the cultural bound term CBT is explained in several words in the TL text (Newmark 1988 b: 83). Componential analysis is a translation procedure in which an SL word / term is transferred to a TL context through a word/ term which has similar meaning but is not an identical equivalent however both terms should have something in common. Newmark also refers to synonymy as a translation procedure which incorporates a new TL equivalent for a SL word / term. Concerning thorough translation, it is a literal translation of common collocations, names of organizations... etc. It is also called calques or loan translation. It is also obvious that shift or transposition is another translation procedure which involves an alteration in the syntactical/grammatical structures from SL to TL context. For example, the change from singular to plural or the change of SL verb into TL noun or SL noun group into a TL noun group .... Etc. These changes are required as a result of semantic and cultural differences in addition to variations in SL and TL systems.

In Approaches to Translation, Newmark argues that modulation is another translation procedure which is used when the translator reproduces the message of the original text in TL context in conformity with the current norms of the TL since the "SL and the TL may appear dissimilar in terms of perspective" (Newmark 1988: 86). Recognized translation is also a translation procedure advocated when the translator uses the officially accepted translation of any institutional term according to Newmark's Approaches to Translation (Newmark 1988b:89). Compensation is a translation procedure which occurs when loss of meaning in one part of a sentence is compensated for in another part (Newmark, 90). Paraphrase is a translation procedure in which the meaning of the culture-bound term CBT is explained in more detail in the TL context than in the case of descriptive 
The Intersection between Language, Culture, Race and Ideology Reflections on the Translation of African-American Literature into Arabic

equivalence (Newmark 1988: 91). Couplets are a translation procedure which is utilized when the translator combines two different procedures in his translation. Using notes is also a translation procedure which provides additional information to the TL text. These notes appear in the form of footnotes or the translator's explanatory notes or introductory remarks. Though excessive footnotes deform the shape of a translation and a translation sprinkled with notes is not desirable, however their use would help the TT readers understand SL texts. On this basis, Nida advocates the use of footnotes to provide supplementary information including the SL texts discrepancies.

\section{The Translation of Culture Specific Discourse in DutChMan}

The difficulty to translate culture specific elements in a literary text leads to omission and lexical loss according to. Newmark's Approaches to Translation. This loss requires compensation on the part of the translator. Newmark's argument that compensation takes place "when loss of meaning in one part of a sentence is compensated in another part" (Newmark 1988: 90) seems relevant in this context. Although culturally implicit translation loss is inevitable in literary texts, compensation takes place through a form of TL dynamic equivalence used to counterbalance such loss and seems an appropriate vehicle to transfer cultural connotations deployed in the SL text. In this context, both the ST lexical function and its cultural implications are transferred as far as possible in the TL text. Therefore, Nida in his discussion of the use of the dynamic equivalence states that "the emotional tone (of the TL text) must accurately reflect the point of view of the (original) author" (Nida 1964: 139).

Moreover, Newmark points out that gestures and habits are "often described in non-cultural language" (Newmark 1988: 103). According to Newmark, a text where gestures and habits are implied but not described in detail makes an entirely communicative translation difficult. In Dutchman, cultural references and allusions about life in the black community in USA in the 1960's which are implicitly disseminated in the text complicates the task of the translator. The lack of SL cultural knowledge on the part of the TT readers force the translator to clarify culture specific structures and expressions loaded with significant cultural knowledge because expressions have different meanings that change from culture to culture as Sapir argues: "no two languages are ever sufficiently similar to be considered as representing the same social reality"(Sapir 1956: 69). Sapir also points out that even lexical items which seem to have an apparently simple translation (such as café) may have a considerably different signification that varies from one culture to another.

In Dutchman, the writer deploys culturally-oriented structures integral to the racial situation and the ethnic turmoil in USA in the 1960's. These culture-specific aspects complicate the text and make its translation a difficult task. In addition to potential obstacles encountered by the translator, TL readers , in the Arab world, will definitely find difficulties in understanding such a text due to lack of knowledge integral to the cultural connotations embedded in the lexica items deployed in the text. For example in her first conversation with Clay, Lula is angry because "I'd turned around and saw you staring through that window down in the vicinity of my ass and legs". Clay replies:'I admit I was looking in your direction. But the rest of that weight is yours"1. In the context of the play the term (weight) refers to the writer's notion about what he calls (the white man's obsession with sexual guilt rooted in the Christian doctrine of Original Sin) which is alien to African American traditions. Apparently the allusion to the sexual burden in the above-cited lines is also alien to the TT reader who comes from another culture. Thus it is advisable to translate the statement literally using a suitable linguistic equivalent in addition to an explanatory note to be inserted by the translator. The note is crucial to a full understanding of the ST because the TT Arab reader is not aware of the Christian concept of the Original Sin.

Further, in her dialogue with Clay, Lula aims to criticize his external appearance because he wears a white man's clothes ignoring his African roots she addresses him in a sarcastic tone saying: "What've you got that jacket and tie on in all this heat for? And why've wearing a jacket and tie like that? Did your people ever burn witches or start revolutions over the price of tea? Boy, those narrow shoulder clothes come from a tradition you ought to feel opposed by. A three button suit. What right do you have to be wearing a three-button suit and striped tie? Your grandfather was a slave, he didn't go to

${ }^{1}$ All citations from Dutchman are extracted from the following book: Jones, Le Roi. Dutchman and the Slave. William Morrow, 1964. 
The Intersection between Language, Culture, Race and Ideology Reflections on the Translation of African-American Literature into Arabic

Harvard". According to the text of Dutchman, the preceding quotation is uttered by Lula, a white lady who symbolizes the American civilization.

These sarcastic lines are addressed to Clay, a middle-class African-American who attempts to be integrated into the white mainstream society, thus, he imitates white Americans in terms of dress and behavior ignoring his racial roots. Explicitly, Lula criticizes Clay's outward appearance, his clothes, his hair style and his language but there are other cultural considerations to be taken into account by the translator. If these lines are translated literally ignoring the references to the historical witchcraft trial in Salem city in a seventeenth-century Puritan America as well as the allusions to slavery and Harvard University, their significance will be lost. To a TL reader in the Arab world, the above-cited extract simply refers to a woman who criticizes a man because she does not like his clothes. Unable to perceive the racist agenda embedded in the culturally loaded vocabulary items, underlined above and dispersed in the SL context, the TL reader would reach conclusions outside the context of the original text.

In another conversation, Lula accuses Clay of being a criminal: "Clay, you are a murderer and you know that". Within the ethnic context of the play, Lula means that Clay kills his black self and black identity by abandoning the cause of his people and their struggle for freedom and equality. However, the reference to Clay as a murderer may cause confusion to a TL reader unaware of the play's cultural background. In a related context, Lula tells Clay: "I bet you never once thought you were black nigger". In response Clay says: "well, in college I thought I was Baudelaire. But I've slowed down since......... My mother was a Republican."Obviously, the reference to the famous French poet (Baudelaire) may be misinterpret by TT readers who are expected to jump to mistaken conclusions. Within the cultural signification of the play, the writer aims to criticize Clay, an epitome of the African-American middle class, who believes that he is superior to the rest of the African- American community "a black Baudelaire". It is relevant to mention that Le Roi Jones in most of his dramatic works during the 1960's castigates the allegations of superiority on the part of the black middle class. Equally, the notion that Clay's mother was a Republican does not mean anything to the TT reader, however this premise is related to the socio-political context of the play. In the sixties the great majority of African-Americans were supporters of The Democratic Party with the exception of middle class folks who mostly support the Republican Party due to their integrationist attitudes. The TT reader's unawareness of foreign culture and the racial situation in USA in the 1960's may lead to trans-cultural misinterpretations unless the translator interferes to bridge the gap between SL and TL texts.

In the second scene of the play Lula tells Clay: "Clay, you liver lipped white man. You would be Christian. You aren't no nigger; you're just a dirty white man. That's all you know...shaking that cream-oil on your knotty head, jackets buttoning to your chin so full of white man's words. Christ..... God.'These utterances which includes a mocking reference to black dialect (You aren't no nigger) underline Lula's perspective that Clay intends to imitate the white man by advocating Anglo-Saxon traditions and religious doctrine (Christianity) in a desperate attempt to be integrated into the mainstream American culture. Putting these utterances in the mouth of Lula, the writer aims to reveal the anti-black tendencies of Clay who even attempts to alter his physical appearance and the shape of his hair. Obviously, a literal translation of these lines will not transfer the spirit of the SL text to a TL context.

In another conversation in the second scene of the play Lula invites Clay to attend a party followed by a visit to her own house: "And with my apple-eating hand I push open the door and lead you, my tender big-eyed prey into... my God, what can I call it... into my hovel". Clay replies: "then what happens?"Lula continues: "After the dancing and games, after the long drinks and long walks, the real fun begins...And you'll call my rooms black as a grave. You'll say "this place is like Juliet's tomb". The preceding extracts include two important lexical structures loaded with cultural connotations that TL/TT readers may fail to understand. First, the reference to the apple as a western traditional symbol of temptation indicates that Lula or white America tempts Clay by offering him false promises of integration (the apples and the party she asks him to attend). Further, Lula, within the complicated symbolic structure of the play, represents Eve who convinces Adam/Clay to eat from the forbidden tree (adoption of western white culture). Consequently, he will be driven out of paradise/America due to current policies of racism and slavery. The second reference is to "Juliet's tomb" which is 
The Intersection between Language, Culture, Race and Ideology Reflections on the Translation of African-American Literature into Arabic

associated with death. The allusion to Shakespeare's Romeo and Juliet alludes to the tragic end of Clay by the end of the play. However, both references, due to their cultural peculiarities, may not be conceived by TT readers who come from a different culture. Therefore the interference of the translator in these situation is inevitable bearing in mind that literal translation will lead to ambiguity on the part of the TT reader.

Afterwards, Lula attempts to provoke Clay by telling him that he is afraid of the white passengers in the subway car where the incidents of the play take place .Lula:"Do all these people frighten You?"

Clay: Why should they frighten me?

Lula: Because you're an escaped nigger. Because you crawled through the wire and made tracks to my side.

Clay: Wire?

Lula: Don't they have wire around plantations?

Clay: You must be Jewish. All you can think about is wire."

Through references to "plantations" Lula aims to remind Clay of the slavery era when blacks were forced to live in plantations surrounded by wires. She attempts to argue that she is superior to him and consequently he has to keep the status quo. Further, the writer's allusion to wires and the analogy between southern American plantations and European concentration camps are integral to the artistic vision of Le Roi Jones. The African American writer points out that his people will inevitably be massacred like European Jews, the victim of the Nazi holocaust, in case they attempt to be integrated into the mainstream white American society. Explicitly, the preceding dialogue includes lexical items loaded with cultural connotations unfamiliar to TL readers. Without the interference of the translator, the analogy between the experience of slavery and the genocide of European Jews during the Nazi holocaust will not be conceived by the TT reader.

In the second scene, Lula decides to insult Clay by showing contempt for his genuine black traditions. She begins to dance in a dirty manner, and then she says: "And that's how the blues was born. The little niggers sitting on a limp, but none of them ever looked like him. Yes, come on Clay. Let's do the nasty. Rub bellies. Let's rub bellies on the train. Does the gritty grind like your old rag - head mammy. Shake it, shake it! Let's do the choo-choo train shuffle, the navel stretcher. The preceding lines, uttered by Lula, not only humiliate Clay by ridiculing his mother but also underestimate respectable African- American traditions viewing "the blues", black music and singing as a kind of belly rubbing. Further, Lula accuses Clay of being an "Uncle Tom", a derogatory term signifying African Americans who approach the white society with a slave-master attitude even in the postslavery era. In the play, the reference to Uncle Tom signifies the submissive middle class negro who is ready to compromise his culture and blackness in order to satisfy the ex-master. Though Clay is delineated as an epitome of Uncle Tom who personifies the policies of submission associated with the black middle class he strongly condemns Lula's degrading allusions particularly to the blues, a cultural tradition rooted in the black history of pain and suffering in USA. Consequently, he becomes furious at Lula threatening to kill her in a brutal way and bringing havoc to the subway car, a symbol of the racist American society in the 1960's: "Oh sit the fuck down. (He moves to restrain her) Sit down, goddamn it ." Due to their unawareness of the socio-historical implications of the terms Uncle Tom" and "blues" in African-American culture, TL readers may misinterpret Clay's reaction to Lula's comments or dismiss it as morally unacceptable. In such situations, the translator should smoothly transfer SL culture specific discourse into TL context using suitable strategies such as componential analysis, modulation, paraphrase and communicative translation.

\section{Translating the Title "Dutchman"}

In literary texts, lexical items with cultural implications complicate the process of translation. For example the title of the text in hand, "Dutchman" creates challenges for the translator and the TT readers as well. In SL culture, and within the African-American cultural context Dutchman alludes to the Flying Dutchman legend which narrates the story of a mythic slave ship destined to sail forever without reaching harbor or anchor. The title allegorically refers to the first slave ship which carried the fist cargo of African slaves from the shores of Africa across the Atlantic to the American 
The Intersection between Language, Culture, Race and Ideology Reflections on the Translation of African-American Literature into Arabic

Diaspora. In other words, the title is intricately woven into the painful history of slavery and the transportation of African slaves to the American South and the Caribbean islands via European vessels carrying Dutch flags . Thus the tile is loaded with cultural signification and historical connotations reflecting the author's aesthetic vision and textual intentions.

To translate the word "Dutchman" literary into Arabic as "Alholandi" using the formal equivalence technique is not sufficient to provide the TT Arab reader with the SL cultural allusions embedded in the title. Inevitably, the title will lose its original meaning as disseminated in the text. For the average, even the educated, Arab reader the lexical item "Alholandi" means someone form the Netherland or someone carrying the Dutch nationality, thus the cultural implications and the racial allusions embedded in the SL title will be lost in translation into Arabic. According to Newmark, the translated title "should sound attractive, allusive, suggestive and should usually bear the same relation to the original (Newmark 1988: 56). Further, the title should carry aspects of the SL dramatic text and convey its spirit to the TT readers. Therefore, in my published translation of the play into Arabic I used the following title: "Alholandi al ta'er: Safinat alabeed" / "The Flying Dutchman: A slave ship" which helps the TT reader to understand the semantic / cultural connotations of the text. In this context, it is apparent that cultural eponyms, like the title "Dutchman", cannot be easily comprehended by TT readers descending from different cultural background without the interference of the translator. Since Arabic speaking readers are not expected to know the cultural connotations of the title it is completely unacceptable to use a formal equivalence in translation because all the meanings of the title will be lost. However, it is possible to neutralize the original term by using an appropriate form of what Newmark calls "componential analysis" in order to transfer the cultural implications of the original term to the TL text. By using compensation as a translation strategy which includes the addition of suitable modifiers to the original term, the cultural implications are automatically transferred to the TL text and the concept will be smoothly conveyed to the TT readers.

\section{Translating Food Traditions}

According to Newmark "food is for many, the most sensitive and important expression of national culture, food terms are subject to the widest variety of translation procedures" (Newmark 1988: 97). In Dutchman, the terms coming under the food category are complicated due to the foreign cultural elements embedded in them. In the beginning of the play, the stage directions show that Lula, the white female protagonist is eating an apple. She addresses Clay, the African-American protagonist saying: "Eating apples together is a always the first step."In SL culture, apples are symbols of temptation according to the biblical narrative. Within the symbolic and racial structure of the play, Lula, a symbol of white America, seeks to tempt Clay, a middle class Negro interested in being assimilated into the American mainstream culture. The apples, in the context of the play, are not only traditional symbols of temptation but also an emblem of the false promises of integration introduced by white America to the Negro middle class population in order to neutralize them during a decade of violent confrontations between blacks and whites in the US in the 1960's.

Due to the importance of the cultural signification of "the apples" as a motif and lexical item, the translator should interfere and provide a footnote to acquaint the TT Arab reader with the cultural connotations of the term in the original culture. This kind of translation is better than using a formal equivalence because it corresponds to the idea of the original signification and it is more appropriate in terms of the function of the translated term in TL context. Moreover, in the first scene of the play, Lula criticizes Clay mocking his outward appearance . She addresses him saying : "You look like death eating a soda cracker". Translating the statement into Arabic using formal equivalence will inevitably lead to the construction of a nonsensical TL utterance:"tabdu methla almawt yaakul soda kraker". In the context of the play and within the framework of American culture, the first part of the statement "you look like death eating...." means "you look pale, tired and anemic". The soda cracker is a kind of dry biscuits baked with soda and it is culturally unfamiliar to the average TT reader. Therefore, the first part of the statement should be translated in an appropriate manner taking into consideration its ST meaning. However the original name of the food should be preserved by transliterating it into Arabic in order to transfer the spirit of foreignness embedded in the SL text.

In the second scene of the play the lexical item "watermelon" appears in the context of Clay's aggressive reaction to Lula's humiliating remarks about his people and his cultural heritage particularly the Blues tradition. He warns Lula of the dangerous consequences of racism which will 
The Intersection between Language, Culture, Race and Ideology Reflections on the Translation of African-American Literature into Arabic

inevitably trigger black violence and retaliation: "they will murder you..... and (consequently ) not a watermelon in sight." To translate "watermelon" in this context literally into Arabic as "batikh" will be absurd and incomprehensible to the TT readers. In American culture and particularly in black dialect the term watermelon refers to a racist person advocating discrimination doctrines. "Watermelon" in this context is close in meaning to the derogatory term "redneck" which refers to racist white folks in the American South who express hostile views against the black minority.

The reference to "watermelon" also has allusions to the slaveholding South and the painful experience of enslavement. In the era of slavery, African slaves were forced to work in Southern plantations growing cotton and watermelons. Clay's utterance "and not a watermelon in sight" means slavery will be completely abolished from the US only when black people are able to kill all racists like Lula. If the abovementioned statement is translated literally into Arabic due to lack of cultural / historical knowledge on the part of the translator, it will lead to embarrassment and confusion on the part of the TT reader. Integral to the culture-specific structure of the above mentioned lexical item and as a result of the lack of background knowledge on the part of the TT reader, the translator should be fully aware of the SL culture, otherwise the entire translation process will be risky. In case the translator is conscious of SL cultural implications he/she can help the TT reader comprehend the SL text by using footnotes and other appropriate strategies to explain SL semantic entanglements and ambiguous cultural phenomena. Bearing in mind Newmark's argument that "the additional information a translator may have to add to his version is normally cultural, (accounting for difference between SL and TL culture) technical or linguistic" (Newmark 1988: 91), it is significant to explain the cultural connotations embedded in the term "watermelon" by adding a footnote.

\section{Translating Names}

Since languages are not nomenclatures and the concept of one language may differ from those of another language (Culler 1976: 20), and since each language articulates the world differently, proper names carry culture specific connotations which should be considered during translation. A proper name refers to the name of "a particular person, place or thing" and is spelled "with a capital letter" (Richard 1985: 68). Obviously, proper names play an essential role in literary texts and they refer to the cultural background, social status and nationality of characters, therefore, they demand some attention when rendered into a foreign language. In a similar context, Newmark in his discussion of the translation of proper names, points out that "people's first and surnames are transferred to preserve nationality and assume that their names have no connotations in the text" (Newmark 1988: 214). However, the procedure of transference becomes insignificant in the case of names which carry semantic connotations and cultural implications. When a character's name is not conceived in a literary text by educated TL readers, it leads to cultural misconceptions which hinder the understanding of the SL text.

Therefore some strategies are suggested to translate SL proper names into TL context. Translation theorists argue that the translator can omit the name and transfer its connotations by other means, i.e., the use of a common noun. The proper name could also be literally translated regardless of its connotative or contextual meaning. Other options are suggested which include the deleting of the name and its allusions, replacing it by a TL item or using a footnote and rephrasing the name's allusions. Newmark suggests a bizarre solution for the translation of proper names which can not fit into Arabic translations of SL texts. He states that it is possible to translate the word that underlines the SL proper name into the TL, then naturalize the translated word back into a new SL proper name.

Apparently, proper names can be translated by adapting SL names to conform to the phonic / graphic conventions of the target language culture or by transliterating SL names into TL contexts. The transliteration dynamics is advocated in this paper in the translation of proper names mentioned in the text of Dutchman. In the literal translation of a particular text the translator also has the option of using the proper name as it is in order to produce an exotic effect in the TT readers. This process, integral to literal translation, involves no cultural translation Cultural transplantation is another strategy which is used in the translation of proper names is an extreme degree of cultural transposition. It is a procedure in which SL names are replaced by indigenous TL names. However these TL names are not considered as literal equivalents of their SL counterparts but they carry similar cultural connotations. 
The Intersection between Language, Culture, Race and Ideology Reflections on the Translation of African-American Literature into Arabic

In Dutchman, proper names are used by the writer to connote a variety of cultural implications and to achieve aesthetic purposes like irony, ridicule and sarcasm. For example, before Lula knows the name of Clay she informs him that she can guess his name : "Lloyd, Norman ? One of those hopeless colored names creeping out of New Jersey. Leonard? Gag.........Y You are too pretentious to be a Jackson or Johnson, Williams, Willie..." Within the socio-ethnic context of the play the abovementioned names belong to two categories. Names like Lloyd, Norman and Leonard belong to the black middle class criticized by the writer and represented in the text by the character of Clay who seeks integration into the white mainstream culture. The other names -Jackson, Johnson, Williams and Willie - belong to the lower class which represents the majority of the African American community who reject the notion of assimilation. The reference to New Jersey alludes to the black middle class population who refuse to stay in poor black areas in Harlem and prefer to live in white dominated suburbs in New Jersey.

Lula's sarcastic reference to the above-cited list of names aims to express her contempt of Clay. She also attempts to uncover his real intentions as a black middle class hypocrite who abandons his folks and culture in an attempt to join the white mainstream society. In a conversation with Lula, Clay, in his turn, criticizes her by saying: "Snow White, baby and do not you forget it."In American culture "Snow White" refers to a popular fairy tale but Clay, the black character in the text uses the term to lampoon Lula. Clay ridicules Lula's white color the same way she makes fun of his black complexion. Within the context of the play, the term "white" has racial connotations, a kind of racism-in-reverse. In African American culture the white color has negative implications and it is associated with racism, death and coldness. Alternately, in white cultural mythology, blackness has many negative connotations. For example, Satan is conceived as an old black man, death is black, the crow is associated with bad omens because the color of the bird is black and the Cain, the son of Adam who kills his brother, Abel, is black. In the light of the preceding argument, it is apparent that an awareness of SL cultural phenomena on the part of the translator is integral to a standard translation of texts loaded with culture specific elements such as proper names. The translator is authorized to use footnotes or any other adequate translation technique such as calques, naturalization and cultural equivalence to explain the cultural implications embedded in these names.

\section{The Translation OF ObSCEnity}

Sexual terms and expressions are deeply engrained in the fabric of culture; therefore, it is impossible to ignore this phenomenon in translation. In the domain of translation, one should be aware of the nature of the sexual terms used in SL culture to determine whether these terms are incorporated for the sake of effecting obscenity and shock or otherwise. In particular circumstances, these sexual terms and expressions are related to politics, economics, class, race and the feminist domain. For example, in feminist texts, there is often a protest against women's body language being interpreted unjustly from a male phallo-centric perspective. Stimulated by Queer studies and research on postcolonial sensitivities, many experts gave more attention to the recurrent appearance of sexual/obscene language in literary texts. Nevertheless the use of sexual language is not often related to phallo centrism or reflection of the protest of marginalities and minorities. But sexual terminology is mostly used to fulfill aesthetic and ideological proposes .In Dutchman the writer deploys sexual discourse in different situations as part and parcel of the racist agenda of the play. As a middle class Negro interested in assimilation, Clay misunderstands Lula's obscene utterances taking her speech as pure sex talk; therefore he will be brutally killed by her at the end of the play. Taking into account the purpose of using sexual language in a given text, the translator should develop appropriate translation techniques to transfer the spirit of the SL text which reflects the intentions of the author.

Due to the multiplicity of connotative registers characterizing obscenity, the translation of words of a sexual nature will vary according to whether these lexical items are evoked implicitly or explicitly, whether they belong to a particular dialect or jargon (sociolect) even whether they possess a given pragmatic function (to shock, to evoke irony, laugher and scorn). Therefore, the translator should take into consideration the cultural context of the SL text in addition to an awareness of the value system operating in the target language culture with regard to the censure of sexuality. The translator should also abandon his own prejudices and biases toward the issue of sexuality and its language particularly those prejudices imposed by the translator's local culture. 
The Intersection between Language, Culture, Race and Ideology Reflections on the Translation of African-American Literature into Arabic

\section{Translating Dutchman AND The Issue OF CENSORShIP}

In Arabic translations of SL texts, rooted in foreign culture, a translator may be obliged to omit sexual language or substitute vulgar words and expressions with neutral scientific language (making love instead of having sex, penis instead of deck, vagina instead of cunt or pussy ...etc.,) in order to adapt the translated text to fit TL cultural norms. The tradition of avoiding vulgarity and slang expressions replacing them with other expressions is deeply rooted in Arabic language particularly in the context of the Holy Koran. The sexual act or the intimate relationship between a husband and his wife is expressed in the holy Koran through an allusive language and euphemism which never violate a conservative value system integral to Islamic culture ("Do not come near women" and "do not touch women" instead of "do not have sex with women"). Nevertheless, when the translator intends to distort the SL text by advocating a discourse of the sexually correct, he/she may rob the readers "of their chance of understanding and even learning about other cultures, other life styles, other realities" (Scandura 2004: 123). In the text of Dutchman, there are many examples of sexuality and obscenity, however, most of them are part of the sexolects and the sexual jargon rooted in the African-American ghetto community in the 1960's. For example Lula in her first conversation with Clay, says : "I'd turned around and saw you staring through that window in the vicinity of my ass and legs". The explicit reference to "my ass and legs" in traditional Arab culture is associated with vulgarity and obscenity particularly because the statement is uttered by a woman. Due to religious norms in a patriarchal society the issue of the female body is part of the cultural Taboo. Further, the sexual language of the female about her body is culturally sensitive and it is associated with vulgarity and obscenity. Thus, these cross-cultural conflicts complicate the translation process on the part of the translator who often distorts the original text by deleting parts of its sexually loaded discourse.

Other examples of obscenity frequently appear in the text of Dutchman such as "abstract asses", "sit the fuck down", "screw yourself", "kiss my ass, kiss my black unruly ass", "up your ass, feebleminded ofay", "as sure as shit", "dumb bitch", "son of a bitch", and other terms connoting homosexuality. Though translation is a transnational / globalized phenomenon, standards of obscenity and pornography and cultural norms concerning sexuality should be considered by translators. For example, the gay phenomenon is accepted in the West but though existing in the Arab world, it is widely recognized as a matter of cultural sensitivity. Therefore, cultural and geographical differences in the perception of sexuality or in the acceptance of sexually explicit language in literary texts targeted for translation should be taken into consideration. For example, the American standards of sexuality as reflected in literary texts often seem prudish to the Arab world and even to people in Europe. On this basis, translators should be aware of how to handle sexual registers and connotations and how to conserve the effect of sexuality. In other words the translator should know when and how to intensify sexuality or tone it down in order to achieve the desired effect on the readers.

Confronted with SL sexual structures that often have no cultural or formal equivalences in the TL (Arabic), the translator may be tempted to omit complete lines or passages from the SL text. Failing to find TL semantic or cultural aspects dealing with vulgarity, sexuality or pornography to replace their counterparts in the SL text, the translator is authorized to make a compromise or an approximation between SL and TL sexual phenomena. The translator of Dutchman has the option to translate SL sexual jargon into TL context using standard or non-standard Arabic. In an attempt to maintain the permitted level of vulgarity concerning offensive language in TL contexts and taking into consideration the cultural and linguistic differences between the sexual imagination of different peoples, the sexual discourse of Dutchman is translated into modern standard Arabic language. Since most of the sexual expressions uttered by the white female protagonist, Lula, aim to arouse Clay sexuall, the use of standard Arabic in translation will tone down the language of sexuality to fit domestic cultural norms. In this context, it is noteworthy to argue that the translator who renders sexual language into Arabic has to adapt or trans-edit the SL text because the process of trans-editing is integral to a culturally acceptable translation and a TL text toned down in sexuality.

\section{CONCLUSION}

As stated throughout the preceding argument, it is relevant to point out that when a text contains cultural specific elements, translation loss is inevitable due to the peculiar nature of the text and the wide differences between source text (ST) readers and TT readers. Therefore, the translator should 
provide missing background information to fill the gap between SL and TL texts. In order to preserve the specific cultural connotations of Dutchman, certain additions should be provided to the target text. This process underlines the notion that formal equivalence should be avoided in such situations because it will thwart the horizons of expectations of the TT reader. Furthermore, it is also noteworthy in this context to use Nida's argument that the use of complete dynamic equivalence does not seem totally acceptable. Instead cultural elements could be kept in order to preserve the original aim of the text in its SL environment. In translating culture specific texts, it is also advisable to avoid the use of either the formal or dynamic equivalence procedures replacing them with a communicative translation approach to ensure that the semantic and cultural content embedded in the SL text is fully acceptable and comprehensible to the TL readership.

\section{REFERENCES}

[1] Bassnett, Susan.Translation Studies. New York: Routledge, 1996.

[2] Cohen, A.D. "On taking tests: what the students report". Language Testing (1984) 11 (1). 70-81.

[3] Culler, J. Structuralist poetics: structuralism, linguistics, and the study of literature. Cornell: Cornell University Press, 1976.

[4] Coulthard, M. "Linguistic Constraints on Translation." In Studies in Translation / Estudos da Traducao, Ilha do Desterro, 28. Universidade Federal de Santa Catarina, 1992.

[5] Gohar, Saddik. "The Empowerment of Teaching Modern English and American Literary Texts to EFL Emirati University Students: New Approach". International Journal of Humanities and Cultural Studies (IJHCS) Vol.1, Issue 3, December 2015. pp:1-13.

[6] Jones, LeRoi. Dutchman and the Slave. New York: William Morrow, 1964.

[7] Krings, H.P. "Translation problems and translation strategies of advanced German learners of French". In J. House, \& S. Blum-Kulka (Eds.), Interlingual and intercultural communication. Tubingen: Gunter Narr, 1986.

[8] Lotman, Yu. M Uspensky, George Mihaychuk. "On the Semiotic Mechanism of Culture". In Soviet Semiotics and Criticism: An Anthology (Winter, 1978), pp. 211-232 republished by The Johns Hopkins University Press, 1987.

[9] Newmark, P. Approaches to Translation. Hertfordshire: Prentice Hall, 1988. A Textbook of Translation. Hertfordshire: Prentice Hall. 1988.

[10] Nida, E. A. Towards a science of translation, with special reference to principles and procedures involved in Bible translating. Leiden: Brill, 1964.

[11] Richards, et al. Longman dictionary of applied linguistics. UK: Longman, 1985.

[12] Sapir, Edward. Culture, Language and Personality: Selected Essays. Berkeley: University of California Press, 1956.

[13] Scandura, Gabriela L. "Sex, Lies and TV: Censorship and Subtitling," Meta, vol. XLIX, n ${ }^{\circ}$ (2004):125134.

[14] Seguinot, C. The translation process. Toronto: H.G. Publications, 1989.

[15] Toury, Gideon. Descriptive Translation Studies and Beyond. Amsterdam/Philadelphia: John Benjamins, 1978.

[16] Veltrusky, Jiri. Drama as Literature. Lisse: The Peter de Ridder Press, 1977.

[17] Venuti, Lawrence. The Translator's Invisibility. New York: Routledge, 1998.

[18] VermeerHans Josef. "Skopos and commission in translational action:. In Readings in translation theory, eds. Andrew Chesterman. Helsinki, Oy Finn Lectura, 1989. 173-187. Translated into English by Andrew Chesterman.

Citation: Saddik Gohar. "The Intersection between Language, Culture, Race and Ideology Reflections on the Translation of African-American Literature into Arabic" International Journal on Studies in English Language and Literature (IJSELL), vol 6, no. 1, 2018, pp. 52-65. doi:http://dx.doi.org/10.20431/23473134.0601008 .

Copyright: (0) 2018 Authors. This is an open-access article distributed under the terms of the Creative Commons Attribution License, which permits unrestricted use, distribution, and reproduction in any medium, provided the original author and source are credited. 